\title{
Platypnea-orthodeoxia syndrome associated with COVID-19 pneumonia: a case report
}

\author{
Takuo Hoshi ${ }^{*}$ (D), Yu Tadokoro², Masaru Nemoto ${ }^{2}$, Junya Honda ${ }^{3}$ and Shihori Matsukura ${ }^{4}$
}

\begin{abstract}
Background: Platypnea-orthodeoxia syndrome (POS) is a rare clinical condition characterized by respiratory distress and/or hypoxia developing in the sitting/upright position, which is relieved in the recumbent position. This syndrome is known to have an intracardiac shunt as its primary etiology. Here, we report the case of a patient who was found to have POS without an intracardiac shunt while recovering from coronavirus disease (COVID-19) pneumonia.
\end{abstract}

Case presentation: A 73-year-old woman was diagnosed with severe COVID-19 pneumonia and was managed according to our institutional protocol. Although her oxygenation improved at rest, oxygen saturation dropped to lower than $80 \%$ when she was in the sitting position. She had no patent foramen ovale or other intracardiac shunts. She showed gradual improvement and was discharged under home oxygen therapy 28 days after admission.

Conclusions: This report highlights the importance of continuous bedside monitoring of pulse oximetry during positional changes, even if it is stable at rest, in patients with moderate to severe COVID-19.

Keywords: Platypnea-orthodeoxia syndrome, COVID-19 pneumonia, Positional change

\section{Background}

Platypnea-orthodeoxia syndrome (POS) is a rare condition first described by Burchell et al. [1] in 1949, which causes hypoxemia when sitting or standing and improves in the supine position. The common etiology of this syndrome is the presence of a right-left shunt, such as a patent foramen ovale (PFO) or an atrial septal defect (ASD) [2]. Here, we report the case of a patient who was found to have POS without an intracardiac shunt during recovery from coronavirus disease (COVID-19) pneumonia. Written patient consent was obtained for the publication of the report, which was prepared according to the CARE guidelines.

\footnotetext{
* Correspondence: 124stern@gmail.com

'Department of Anesthesiology and Critical Care Medicine, Ibaraki Clinical Education and Training Center, University of Tsukuba, Koibuchi 6528, Kasama, Ibaraki 309-1793, Japan

Full list of author information is available at the end of the article
}

\section{Case presentation}

A 73-year-old woman (height, $157 \mathrm{~cm}$; weight, $43 \mathrm{~kg}$ ) visited a physician 7 days before admission to our hospital for dizziness, loss of appetite, and fatigue, but no specific issues could be determined, and the patient returned home without receiving treatment. On the day of admission, she revisited the physician because she had a fever of $38^{\circ} \mathrm{C}$ and dyspnea. Her oxygen saturation was $86 \%$ in ambient room air, and nasopharyngeal swab polymerase chain reaction for SARS-Cov-2 revealed that she had COVID-19. The patient was transferred to our hospital under oxygen administration for respiratory management.

When the patient arrived at our hospital, her oxygen saturation was $87 \%$ (blood pressure, 152/68 $\mathrm{mmHg}$; heart rate, $73 \mathrm{bpm}$ ) with oxygen administered at $2 \mathrm{~L} / \mathrm{min}$ via a nasal cannula. We changed the oxygen administration method to OxyMask ${ }^{\mathrm{TM}}$ (Southmedic Inc., Barrie,

\section{Springer Open}

(ㅇ The Author(s). 2021 Open Access This article is licensed under a Creative Commons Attribution 4.0 International License, which permits use, sharing, adaptation, distribution and reproduction in any medium or format, as long as you give appropriate credit to the original author(s) and the source, provide a link to the Creative Commons licence, and indicate if changes were made. The images or other third party material in this article are included in the article's Creative Commons licence, unless indicated otherwise in a credit line to the material. If material is not included in the article's Creative Commons licence and your intended use is not permitted by statutory regulation or exceeds the permitted use, you will need to obtain permission directly from the copyright holder. To view a copy of this licence, visit http://creativecommons.org/licenses/by/4.0/. 
ON, Canada) at $7 \mathrm{~L} / \mathrm{min}$, and her oxygen saturation increased to $92 \%$. Subsequently, she was admitted to the intensive care unit. Although she had no underlying conditions that would increase her risk for severe COVID-19, shortly after admission, her oxygen saturation dropped to approximately $90 \%$ and her respiratory rate increased to $40 / \mathrm{min}$. We decided to start high-flow nasal cannula therapy at $50 \mathrm{~L} / \mathrm{min}, \mathrm{FIO} 250 \%$.

Her hemogram showed a white blood cell count of $7400 / \mu \mathrm{l}$ and hemoglobin $12.4 \mathrm{~g} / \mathrm{dl}$. Her blood biochemistry tests only showed mild elevation in transaminases (glutamic oxaloacetic transaminase, $46 \mathrm{U} / \mathrm{l}$; glutamic pyruvic transaminase, $36 \mathrm{U} / \mathrm{l}$ ), and her renal function tests and electrolytes were within the normal limits. Arterial blood gas analysis performed before high-flow oxygen therapy was suggestive of type 1 respiratory failure (pH, 7.496; $\mathrm{PO}_{2}, 52.2 \mathrm{mmHg} ; \mathrm{PCO}_{2}, 28.5 \mathrm{mmHg}$ ). Initial chest computed tomography (CT) (Fig. 1) showed bilateral and peripheral predominant consolidation and an air bronchogram.

She was managed according to our institutional protocol (inhalational oxygen concentration, steroids, anticoagulation, tocilizumab, rehabilitation) and maintaining oxygen saturation $92 \%$. Although she temporarily needed an $\mathrm{FIO}_{2}$ of 0.8 to maintain her peripheral oxygen saturation, we did not intubate her because she did not exert effort during ventilation, she strongly preferred not to be intubated, and her only symptom was lightheadedness when standing. On the 11th day of hospitalization, although her oxygen saturation decreased with light exertion but stabilized at rest in the supine position, we changed the oxygen administration method to OxyMask $^{\mathrm{TM}} 8 \mathrm{~L} / \mathrm{min}$. Although oxygen saturation was maintained when the patient was at rest and in the supine position, it dropped to lower than $80 \%$ when the patient was in the sitting position after, for instance, moving to a portable toilet. Moreover, more than 30 min was needed for oxygen saturation to increase even after starting high-flow oxygen therapy with fraction of inspiratory oxygen 0.5 or higher. However, $\mathrm{SpO} 2$ rapidly recovered when the patient was repositioned to the supine position. We suspected the presence of a rightleft shunt, which increased with change in position, and asked the cardiologist to search for a PFO or ASD. We

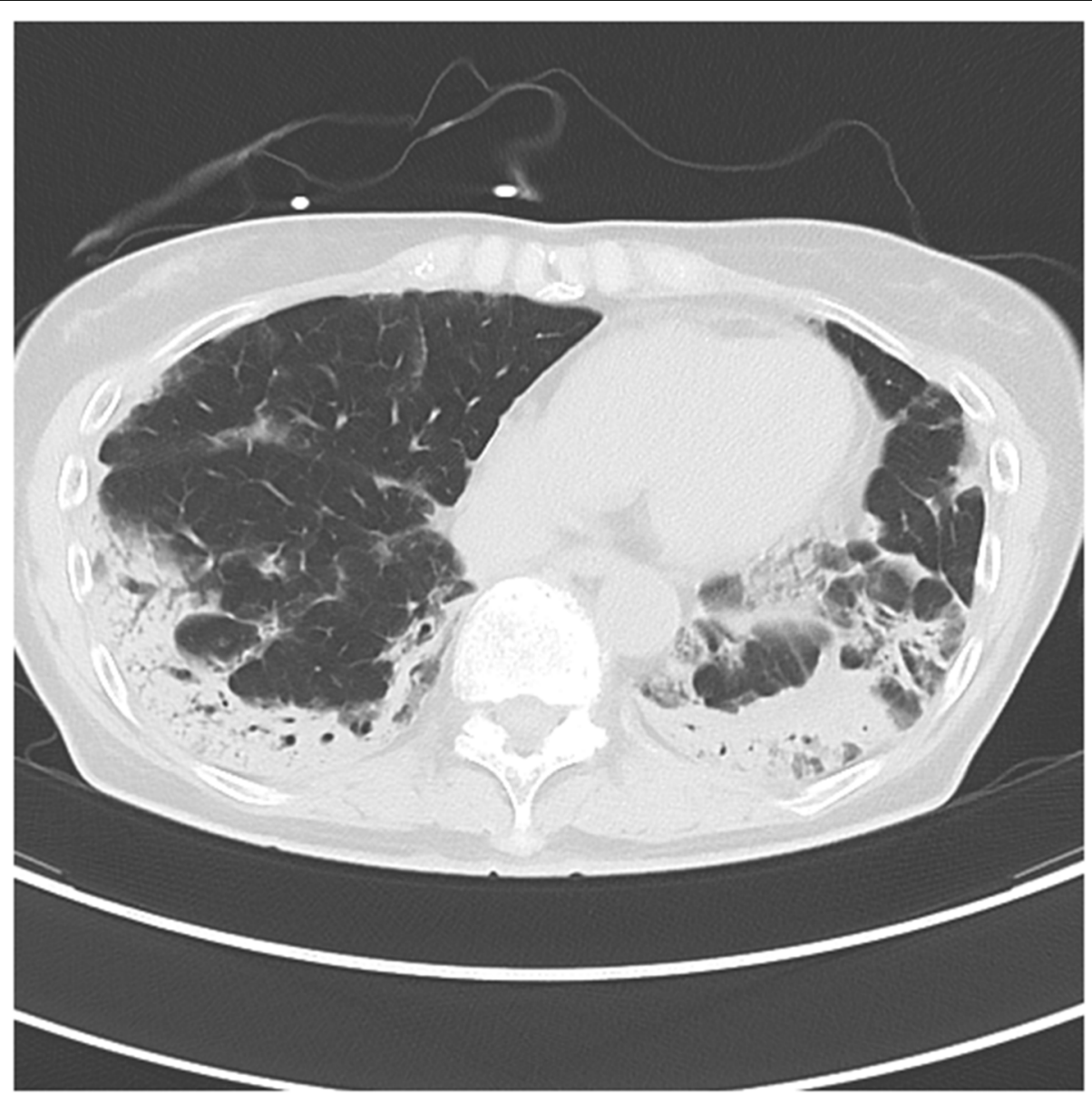

Fig. 1 Initial chest computed tomography $(C T)$ showed bilateral and peripheral predominant consolidation and air bronchogram 
performed contrast-enhanced CT and echocardiography but could not find an intracardiac shunt. Afterward, although her oxygen saturation slightly decreased when she sat or stood, her oxygenation slowly improved, and she was discharged under home oxygen therapy with $0.5 \mathrm{~L} / \mathrm{min}$ via a nasal cannula 28 days after admission.

\section{Discussion}

We reported the case of a patient with POS secondary to COVID-19 pneumonia. POS is a rare syndrome characterized by dyspnea and hypoxia in the sitting or upright position from a recumbent position and fall in oxygen saturation by more than $5 \%$ [3]. The mechanism of POS can be classified based on intracardiac abnormalities, extracardiac abnormalities, and miscellaneous etiologies [2, 3], and a PFO is the most commonly reported etiology of this syndrome, and few cases related to lung parenchymal disease have been reported [3].

Reported causes of POS include parenchymal lung disease, interstitial lung disease, and adult respiratory distress syndrome [3, 4], and POS caused by COVID-19 was first reported in 2020 [5]. In patients with COVID19 , posterior and lower zone parenchymal involvement and gravitational shunting of blood to the lower zones to wasting of ventilation are common [6]. Wasting of ventilation is also exaggerated in the presence of microthrombi and microangiopathy observed in severe COVID-19 [7]. In the present case, contrast-enhanced CT showed no obvious pulmonary emboli, but the Ddimer was slightly high at $1.4 \mu \mathrm{g} / \mathrm{ml}$ at admission, indicating the possible presence of a microthrombus. Patients with COVID-19 reportedly have varying degrees of pulmonary fibrosis and lung dysfunction, necessitating careful monitoring [8]. Lung lesions caused by COVID19 often occur in the subpleural area of the lower lobes of both lungs [9], and in our patient, the basal part of both lungs was predominantly affected by the interstitial pneumonia's fibrotic evolution. As gravity promotes blood flow more to the basilar areas of the lung, the apical lung zones show increased dead space ventilation. Lower lung-predominant parenchymal disease may worsen this physiological ventilation-perfusion mismatch, resulting in POS.

Furthermore, in our patient, the physiological shunt as well as the wasted ventilation was amplified by the disproportionate reduction of ventilation with respect to the reduced perfusion when shifting from recumbent to the sitting or standing position. Her physiological shunt and waste ventilation were improved by rehabilitation and inflammation improvement, and the patient could be discharged under home oxygenation therapy. Although COVID-19 pneumonia predominantly affects the basal segments of both lungs, it remains unclear why
POS is not observed in all COVID-19 pneumonia cases. In our case, D-dimer was only measured at the time of admission, but we speculate that the physiology of the vascular bed may have significantly changed because of the progression of the pulmonary microembolism and subsequent vascular changes; reviewing the blood test schedule may help in early detection.

\section{Conclusions}

POS is a rare syndrome and should be considered in the differential diagnosis of dyspnea and refractory hypoxemia during rehabilitation of moderate to severe COVID-19 pneumonia. It is crucial to diagnose and determine its etiology to provide appropriate management.

\section{Abbreviations}

ASD: Atrial septal defect; CT: Computed tomography; FIO2: Inhalational oxygen fraction; PCO2: Partial pressure of arterial carbon dioxide; PFO: Patent foramen ovale; $\mathrm{pH}$ : Potential of hydrogen; PO2: Partial pressure of arterial oxygen; POS: Platypnea-orthodeoxia syndrome

\section{Acknowledgements}

The authors would like to thank Editage for English language editing.

\section{Authors' contributions}

$\mathrm{TH}$ : reviewed the literature and wrote this initial manuscript. $\mathrm{YT}, \mathrm{MN}, \mathrm{SM}, \mathrm{JH}$ : provided medical care to this patient and assisted in data collection and the preparation of the manuscript. All authors approved the final version of the manuscript and agreed to be accountable for all aspects of the work in ensuring that questions related to the accuracy or integrity of any part of the work are appropriately investigated and resolved.

Funding

The authors declare that they have received no funding

Availability of data and materials

Not applicable.

\section{Declarations}

Ethics approval and consent to participate

Not applicable.

Consent for publication

Written informed consent was obtained from the patient for publication of this case report.

\section{Competing interests}

The authors declare that they have no competing interests.

\section{Author details}

'Department of Anesthesiology and Critical Care Medicine, Ibaraki Clinical Education and Training Center, University of Tsukuba, Koibuchi 6528, Kasama, Ibaraki 309-1793, Japan. ²Department of Vascular and Endovascular Surgery, Ibaraki Prefectural Central Hospital, Kasama, Japan. ${ }^{3}$ Department of Cardiovascular Medicine, Ibaraki Prefectural Central Hospital, Kasama, Japan. ${ }^{4}$ Department of Respiratory Medicine, Ibaraki Prefectural Central Hospital, Kasama, Japan.

Received: 13 July 2021 Revised: 11 August 2021

Accepted: 21 August 2021 Published online: 31 August 2021

\section{References}

1. Burchell HB, Helmholz HF Jr, Wood EH. Reflex orthostatic dyspnea associated with pulmonary hypotension. Am J Physiol. 1949;159:563-4. 
2. Cheng TO. Platypnea-orthodeoxia syndrome: etiology, differential diagnosis, and management. Catheter Cardiovasc Interv. 1999;47(1):64-6. https://doi. org/10.1002/(SICI)1522-726X(199905)47:1<64::AID-CCD15>3.0.CO;2-6.

3. Agrawal A, Palkar A, Talwar A. The multiple demensions of PlatypneaOrthodeoxia syndrome: A review. Respir Med. 2017;129:31-8. https://doi. org/10.1016/.jmed.2017.05.016.

4. Khan F, Parekh A. Reversible platypnea and orthodeoxia following recovery from adult respiratory distress syndrome. Chest. 1979;75(4):526-8. https:// doi.org/10.1378/chest.75.4.526

5. Tan GP, Ho S, Fan BE, Chotirmall SH, Tan CH, Lew SJW, et al. Reversible platypnea-orthodeoxia in COVID-19 acute respiratory distress syndrome survivors. Respir Physiol Neurobiol. 2020;282:103515. https://doi.org/10.1016/ j.resp.2020.103515

6. Wang Y, Dong C, Hu Y, Li C, Ren Q, Zhang X, et al. Temporal changes of CT findings in 90 patients with COVID-19 pneumonia: a longitudinal study. Radiology. 2020;296(2):E55-64. https://doi.org/10.1148/radiol.2020200843.

7. Fox SE, Akmatbekov A, Harbert JL, Li G, Brown JQ, Heide RSV. Pulmonary and cardiac pathology in African American patients with COVID-19: an autopsy series from New Orleans. Lancet Respir Med. 2020;8(7):681-6. https://doi.org/10.1016/S2213-2600(20)30243-5.

8. Raghu G, Wilson KC. COVID-19 interstitial pneumonia: monitoring the clinical course in survivors. Lancet Respir Med. 2020;8(9):839-42. https://doi. org/10.1016/S2213-2600(20)30349-0

9. Zhao X, Liu B, Yu Y, Wang X, Du Y, Gu J, et al. The characteristics and clinical value of chest $C T$ images of novel coronavirus pneumonia. Clin Radiol. 2020;75(5):335-40. https://doi.org/10.1016/j.crad.2020.03.002.

\section{Publisher's Note}

Springer Nature remains neutral with regard to jurisdictional claims in published maps and institutional affiliations.

\section{Submit your manuscript to a SpringerOpen ${ }^{\circ}$ journal and benefit from:}

- Convenient online submission

- Rigorous peer review

- Open access: articles freely available online

- High visibility within the field

- Retaining the copyright to your article

Submit your next manuscript at $\boldsymbol{\nabla}$ springeropen.com 